\title{
Social reality depicted in the poems of Acharya
} Jankivallabh Shastri

\section{आचार्य जानकीवल्लभ शास्त्री की कविताओं में चित्रित सामाजिक यथार्थ}

*Bala

Research Scholar, Department of Hindi, University of Rajasthan, Jaipur

\begin{abstract}
English
Shastri ji has closely observed the current circumstances of his time, has experienced and has tried to constantly fill the heat with his creative power by standing up against the forces of resistance. In this sequence, he has given a detailed shape to his lifeexperience. Shastri ji does not know how to create any model for himself. He has created a new paradigm for its development and excellence. Shastri ji's personality is as multifaceted, his writing talent is more unique that Shastri ji has had a huge impact on the circumstances of the time, but Shastri ji is a believer in creating writing culture by his nature, not by influence.
\end{abstract}

Keywords: stereotypes, superstitions and social inequalities, progressive values, social reality

\begin{abstract}
Hindi
शास्त्री जी ने अपने समय की सामयिक परिस्थितियों को बारीकी से देखा है, अनुभव किया है और प्रतिरोधी शक्तियों के विरोध में अपने को खड़ा करके अपनी रचनात्मक शक्ति से निरन्तर ताप भरने की कोषिष की है। इस क्रम में उन्होंने अपने जीवन-अनुभव को विस्तृत आकार प्रदान किया है। शास्त्री जी अपने लिए कोई प्रतिमान गढ़ना नहीं जानते। उन्होंने मान-सम्मान उसके विकास और उत्कर्ष के लिए एक से एक नये प्रतिमान गढ़े हैं। शास्त्री जी का व्यक्तित्व जितना बहुमुखी है, उनकी लेखन प्रतिभा उतनी ही अधिक विलक्षण है कि शास्त्री जी पर तत्कालीन परिस्थितियों का वियुल प्रभाव पड़ा है लेकिन शास्त्री जी प्रभाव से नहीं अपने स्वभाव से लेखन संस्कार का निर्माण करने के विष्वासी है।
\end{abstract}

मुख्य शब्दः रूढ़ियों, अंधविष्वासों और सामाजिक विसंगतियों, प्रगतिषील मूल्यों, सामाजिक यथार्थ

\section{Article Publication}

Published Online: 15-Dec-2021

*Author's Correspondence

8 Bala

9 Research Scholar, Department of Hindi, University of Rajasthan, Jaipur

$\triangle$ balachoudhary300[at]gmail.com

(C) 2021The Authors. Published by RESEARCH REVIEW International Journal of Multidisciplinary. This is an open access article under the CC BY-

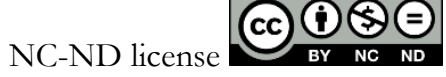

(https://creativecommons.org/licenses/ by-nc-nd/4.0/)

छायावादोत्तर काव्य धारा में जन्मे प्रमुख कवि आचार्य जानकीवल्लभ शास्त्री के काव्य में परम्परा, प्रगति और प्रयोग के परिदृश्यों के साथ भारतीय संस्कृति के प्रगतिशील मूल्यों के साथ सामाजिक यथार्थ का चित्रण भी प्रचुर मात्रा में देखने को मिलता है। संस्कृत भाषा साहित्य के सफल सर्जक आचार्य जानकीवल्लभ शास्त्री महाप्राण निराला की प्रेरणा से हिन्दी साहित्य में लेखन की ओर उन्मुख हुए और निराला के समान ही समाज में विद्यमान रूढ़ियों, अंधविश्वासों और सामाजिक विसंगतियों पर कड़े प्रहार किये। शास्त्री जी का सर्जक व्यक्तित्व समाज में विद्यमान जड़ताओं को नकारता हुआ कलात्मक-सौष्ठव और प्रगतिशील सामाजिक यथार्थ मूल्यों को संतुलित करता अबाध गति से सौन्दर्य और सर्जन के अनछुए पृष्ठों को अब भी खोल रहा है। व्यर्थ लीक-पीटना इन्हें गँवारा नहीं। वे तो नित नए-नए सुघड़ रास्ते गढ़ते हैं। शास्त्री जी ने अपने समय के समाज में विद्यमान सामाजिक बुराइयों का खुलकर विरोध किया व समाज के मध्यम वर्ग का यथार्थ चित्रण कर उसके प्रति सहानुभूति प्रकट की।

शास्त्री जी ने अपनी काव्य रचना 'मेघगीत' में बादल को केन्द्र में रखकर जीवन की त्रासदी, समाज की विसंगति और मनुष्य की विभाजित मानसिकता का द्वन्द्व, शोषण, दोहन, अनाचार, व्यभिचार, कदाचार और भ्रष्टाचार के विरोध में बुलन्द आवाज उठाई। शास्त्री जी यथार्थवादी कवि हैं अतः इन्होंने युग के यथार्थ का चित्रण अपनी साहित्यिक कृतियों के माध्यम से किया है। युग के नीतिविहीन राजनीतिज्ञों के सिद्धान्तों पर गहरी चोट प्रस्तुत करती हुई पंक्तियाँ दृष्टव्य हैं- 
“ऊपर-ऊपर पी जाते हैं, जो पीने वाले हैं,

कहते : ऐसे ही जीते हैं, जो जीने वाले हैं,

इस नृशंस छीना-झपटी पर फट कपटी पर उन्मद बादल,

मूसलधार शतधार नहीं बरसता है।"1

शास्त्री जी ने यहाँ सामाजिक यथार्थ का चित्रण करते हुए जनता का पक्ष लिया है -

"जनता धरती पर बैठी है, नभ में मंच खड़ा है,

जो जितना दूर यही से, उतना वही बड़ा है।"2

आचार्य जानकीवल्लभ शासत्री की काव्य यात्रा में उनकी काव्य रचना 'गाथा' का महत्त्वपूर्ण स्थान है, इसमें सात गाथाएँ हैं। दो आँखें आत्मकथात्मक शेली में लिखी गई गाथा है। इसमें दरिद्रता से अभिशप्त सामाजिक जीवन की यथार्थ झाँकी मिलती है। एक किशोर की माँ उसे कवि के बिस्तर के पास इसलिए भेज देती है कि वह अर्थ-दोहन कर सके।

यहाँ कवि समाज में विद्यमान सामाजिक बुराई का यथार्थ चित्रण करता हुआ असाधारण धैर्य का परिचय देता है। लड़की का वर्णन करते हुए रूप काव्य का चितेरा कवि महता है-

"सिहर गये सब अंग, भर गये दृग, जुड़ा गये प्राण,

प्रथम दृष्टि की प्रीति पढ़ ली, देखा पहली बार।"3

दूसरी गाथा 'आँधी' में एक गरीब मलाहिन की बनारसी व्यथा का चित्रण यथार्थ शैली में किया है इसकी विषय वस्तु अत्यन्त दयनीय है। बिरजू बाबू के घर काम करने वाली कबूतरी की बेटी आंधी गाँव पर शीतला के प्रकोप के कारण भागकर माँ के पास चली जाती है। सम्पन्न वह दरिद्रा कभी-कभी कवि के एकांकी जीवन पर दया दिखाकर घर में मोती बरसा जाती, किन्तु यह सुनकर कि कवि का ब्याह हुआ है, अपने भावों को संकुचित कर लेती है। कवि इस कथा का समापन गांधी युग पर ईषत् व्यंग्य के साथ करता है -

"ऐसी कितनी आँधी आती-जाती बारह मास,

आँधी की 'इति' या कि 'ह्वास', गाँधी-युग का इतिहास।'4

'सुहागरात' तीसरी गाथा है जिसमें कवि ने सामन्ती समाज में विद्यमान सामाजिक बुराइयों का यथार्थ चित्रण किया है जो अपनी पत्नी का परित्याग कर दासियों की संगति में ही अपनी लिप्सा शान्त करता है-

"यह सुहागरात, कुँवर पीते पैमाने भर-भर,

यह सुहाग की रात काँपती बिन्दुमती थी थर-थर।"5

'हरिहर क्षेत्र का मेला' चौथी गाथा है। इसमें कवि ने मेले की विशेषताओं को स्थानीय रंगों के साथ चित्रित करते हुए कवि ने साहित्यिक गरिमावली पुस्तकों की विक्रय-स्पर्धा पर यथार्थ का प्रश्नचिह्न लगाया है-

"श्रेष्ठ किताबें हिन्दी लिट्रेचर की कितनी आयीं

गुलबकावली से ले लेता-मैना के सब भाग

सिंहासन बत्तीसी में छत्तीसी, शीशी कार्क ।"6

'कलियुग के कृष्ण' में एक जमींदार की कथा है जो पहली पत्नी से असन्तुष्ट होकर कॉलेज की छटी छंटंगी गोरी से विवाह कर लेते हैं।

'कल्कि अवतार' में धर्म के आडम्बरों के सहारे, बहनों के विवाह हेतु अर्थोपार्जन का नाटकीय कौतूहल खड़ा किया गया है। 'क्लाइमेक्स' में कवि द्वारा किसी विधवा के उत्तम स्पर्श का कामातुर अंगीकार नहीं वत्सल पुलक की स्वीकृति प्रतिकार का प्रहार 'उर्वशी अर्जुन' गाथा की अस्पष्ट याद दिला देता है-

“इतना स्नेह न भरो रंगो में, मैं सकता न संभाल,

वार पुत्र घर करना चाहो, पहले दे दो ढाल।'7 
छायावाद और प्रगतिवाद के लगभग संधिकाल की यह रचना प्रयोग की मिट्टी का संधान कर रही है। छायाकाल का रूपवर्णन, प्रगतिकाल का दृष्टिकोण और द्विवेदी काल की नायक मर्यादा के साथ प्रयोग की तरणी पर चढ़ी 'गाथा' अपनी आप में विलक्षणताओं की समविष्ट है।

"नयनों से कर रस दान तनिक अधरों पर धर मुसकान तनिक,

दूध में रूम-रूम, सुख में झुम-झुम बढ़ता चलत योगी रमता!"8

शास्त्री जी ने अपनी काव्य-रचना 'गौरी-सरकार' में व्यंग्य के माध्यम से तत्कालीन अंग्रेजी राज व्यवस्था पर करारा व्यंग्य यथार्थवादी शेली में किया है। 'बादल राग' छ: खण्डों का गीत है। इसमें कवि ने अंग्रेजों के प्रति तीखा व्यंग्य इस प्रकार किया है -

“फूलों का शृंगार? अरी ओ माँटो वाली डाली

अमृत क्षरण की छलना? ओ री गरल उगलती प्याली।"9

शास्त्री जी ने भिक्षुक रचना में भी तत्कालीन भारतीय समाज में विद्यमान बुराईयों का चित्रण किया है -

"वह निरंग कंगाल, भग्न कंकाल, श्वास उच्छ्वास हीन सा

भृकुटि बंक दृग मृग सशड, निज छाह में छिपा भाव लीनसा।'10

अर्थात् इस कविता में कवि शास्त्री जी ने प्रगतिवादी कवि निराला की भांति समाज में दीन-हीन एक गरीब भिखारी की सामाजिक दशा का यथार्थ चित्रण किया है। निराला की भांति ही कवि ने 'बादल राग' कविता की रचना की और उसमें बादल को क्रान्ति का प्रतीक बताकर समाज को संदेश दिया। जिसमें उन्होंने अपनी ज्वाला को लाल बादलों के माध्यम से व्यक्त किया है।

"मेरी ज्वाल लाल स्वर्णिम, इस पर काली छाया न करो

बादल तुम मेरे नभ में, घिर-घिर कर फिर-फिर आया न करो।"11

महाप्राण निराला की तरह शास्त्री जी को बसन्त और बादल अधिक प्रिय हैं। बसन्त रंग राग, उमंग-उल्लास विखेरता है सन्नाटे को सरगम में परिणत कर देता है। बाललता में कवि का हृदय विराट और विपुल आवेगों से सम्पृक्त ईमानदारी से झंकृत हुआ है। बाललता कवि के प्रगतिशील जीवन मूल्यों को प्रकट करने वाली उत्कृष्ट रचना मानी गई है इसमें कवि देश के लोगों को सामाजिक यथार्थ का संदेश दे रहे हैं।

\section{“ऐसी ठोकर दो मिजराब की अदा से! गूँज उठे \\ सन्नाटा सुरों की अदा से!!}

ठण्डे सांचों में मैं ज्वाल ढाल पाऊँ! और कसो तार मैं

तार सप्तक में गाऊँ!!'12

शास्त्री जी काव्य रचनाओं में राष्ट्रीय चेतना की अनुगूँज भी दृष्टव्य है जो विशेषकर उनकी गजलों में भी देखने को मिलती है-“'देश दुनिया का था सिरमौर, हमीं भूल गए। नज़र गगन में गड़ाई कि जमीं भूल गए।"13

दूसरी ओर शास्त्री जी ने अपनी काव्य-रचनाओं के माध्यम से युगीन मूल्यों के विघटन की बात की है, सामाजिक विसंगतियों का अंकन है-“'रौशनी तेज, रौशनी मद्धम/किस अँधेरे को रौशनी का गम / .......। पैरवी की पहुँच कहाँ तक है?/चाँद सूरज पर उड़ रहे परचम।"14

आचार्य जानकीवल्लभ शास्त्री जी काव्य-रचना 'धूपतरी' के गीत 'नवगीत' है। नयी संवेदना और नयी जीवन आस्था को सौन्दय्र की लोक-बोधी संस्कार देने वाली कृति है। नवगीत की मूलभूत विशेषताएं हैं -गीत के कथ्य का विस्तार, युग बोध की अभिव्यक्ति, सामाजिक यथार्थ का अंकन, औदात्य सम्पन्न, वस्तुपरकता, नवीन अभिव्यंजना, शिल्प तथा बिम्बपरक भाव। धूपतरी के अधिसंख्यक गीतों में प्रकृति का प्रभावकारी अंकन हुआ। वस्तुतः उनके काव्य में प्रकृति के क्रिया-कलापों को जीवन के क्रियाकलापों के समानान्तर रखकर कुछ विशिष्ट अभिव्यक्ति प्रस्तुत की है। निरन्तर क्षरित होते हुए उच्चतर मानवीय मूल्यों को वे प्रकृति के अक्षय कोष से संयुक्त कर पुनः पुष्ट करना चाहते हैं। 'धूपतरी' के गीतों में देश-काल का यथार्थ भी चित्रित है। नैतिकहीनता, राजनीति, संवेदना-रहित, सम्बंध बंटता हुआ और सिमटता हुआ समाज, अवसरवादी लेखन, 
संकटापन्न जीवनादर्श सभी का संवेदना पूरित चित्रण प्रस्तुत है। इसके गीतों में आशा-निराशा, वेदना-करूणा, राग-चिराग, प्रकृति-पुरूषार्थ, निजता-परता, क्षोभ-आस्था सभी गीतों में रूपायित है। 'धूपतरी' के असंख्य गीतों में प्रकृति का प्रभावकारी अंकन हुआ है- प्रतीक व बिम्बों के माध्यम से।

रंग भरे स्वर, तालगंध की! कसी हरी-सुनहरी शिराएँ,

हँसमुख बहतु के प्राण बंध की! तोड़-तोड़ मिट्टी की परतें।

शास्त्री जी ने अपनी काव्य-रचनाओं में ऐसे भावों को अंकित कर विषमताग्रस्त रोग से गले समाज के प्रति कुशल शिल्पी की तरह आक्रोश की उष्ण धारा प्रवाहित कर क्रान्ति का संदेश दिया है, जो स्पष्टतः कवि की प्रगतिशील चेतना का द्योतक है। कवि जानकी वल्लभ शास्त्री ने आज के समाज के यथार्थ को खुली आँखों से देखा है। मनुष्य को सामाजिक यथार्थ के घोर संकट काल में आचार्य जानकीवल्लभ शास्त्री की आवाज जीवन और सौन्दर्य का भरोसा देती है। जीवन ऊर्जा, प्राण-रस, प्रकृति-समन्वय, समग्र-समरूपता व्यवहारिक संतुलन, अध्यात्म और विज्ञान-विश्वासी इस कविर्मनीषी का स्वर सच्चे और बड़े साहित्यकार का स्वर है-

"फिसले नहीं चले चट्टानों पर, इतनी मनमानी,

आँख मूंद तोड़े गुलाब, कुछ चुभे क्या नादानी

अजी शिखर पर जो चढ़ना है तो कुछ संकट झेलो

चुभने दो दो चार खाए फिर जीभर गुलाब ले लो,

मत हो हताश, दुनियाँ भला-बला है

जीना भी एक कला है।'15

प्रजातांत्रिक व्यवस्था में अराजकता राजनीति के संवाहक तथाकथित राजनेताओं के जन-विरोधी आचरण को अचूक भेदते हुए बेदर्द करने का काम शास्त्री जी ने अपनी काव्य रचना 'मेघगीत' के बहाने किया है। सामाजिक व्यंग्य की तीखी मार बड़ी ही सुगमता से शासत्री जी अपनी रचनाओं में करते हैं। हँसते-हँसते भाव-विह्वल कर देना और करूणा से भर देना इनकी आत्मपगी शैली की विशिष्टा है। समसामयिक संदर्भों, राजनीतिक आचरणों, व्यवस्थागत त्रुटियों और समकालीन विरूपताओं को लक्ष्य करके पर्याप्त रचनाएं पाठकों के सामने आयी हैं।

शास्त्री जी की रचनाएं सामाजिक संघर्ष का आह्वान करती हैं, मूल्यों के प्रति सचेत करती हैं, संवेदना को जागृति के लिए सजग करती है। सही मनुष्य के निर्माण के लिए कसौटी गढ़ती है। एक अटूट जीवन शृंखला है जिसमें सबको अपने दायित्व और कर्तव्य का बोध होना चाहिए। यह अनुभव कराती है। शास्त्री जी की कविताएं प्रकाश-मीनार की तरह अंधकार में पथ-प्रदर्शन कराती हुई प्रगतिशील जीवन मूल्य और संघर्ष की प्रेरणा देती है।

आचार्य जानकीवल्लभ शास्त्री की रचना 'धूपतरी' के गीत 'नवगीत' है। नयी संवेदना और नयी जीवन आस्था को सौंदर्य की लोक-बोधी संस्कार देने वाली कृति है। 'धूपतरी' माहेश्वर तिवारी की अनुशंसा है इसमें एक साथ परम्परा समर्थक, प्रयोगशील तथा प्रगतिशील कवि की अक्षय कृति है। प्रतिबद्धताओं और साँचों से मुक्त मानवीय सामाजिक यथार्थ तथा सांस्कृतिक जिजीविषा के प्रति प्रतिबद्ध कवि हैं। शास्त्री जी की इस रचना में कुल 45 गीतों का संग्रह किया गया है। 'धूपतरी' में 'उदेबादल' 'और नरीतो', 'देश हजारा', 'स्याह सफेद', 'बादल उलझा', 'अनगाया गीत', 'सपन सुहाने' आदि महत्त्वपूर्ण रचनाएं हैं।

'धूपतरी' के गीतों में सामाजिक संघर्ष की अनुभूति बड़ी सच्ची और तीव्र है जो कवि की रचना मात्र में स्वाभाविक रूप से फूट पड़ी है। ऐसी संवेदनाओं को कवि नकार नहीं पाया है। कवि ने समाज में दिखे संघर्ष का यथार्थ चित्रण किया है जिन्दगी की यह संघर्ष-भरी कहानी अनकही रह जाती है, जो शास्त्री जी की निम्न पंक्तियों में द्रष्टव्य है -

"जिन्दगी की कहानी रही अनकही

दिन गुजरते रहे, सांस चलती रही!

अर्थ क्या? शब्द ही अनमने रह गए,

कोष से जो खिंचे तो तने रह गए,

वेदना आँसू पानी बनी, बह गयी, 
धूप ढलती रही, छाँह छलती रही।"16

शास्त्री जी को अपने समय में घोर सामाजिक संघर्ष का सामना करना पड़ा परन्तु कवि को जीवन की प्रतिकूल परिस्थितियों से कोई शिकायत नहीं रही और न ही वे आत्मदया के शिकार हुए। उन्होंने दुःखों से डटकर टक्कर ली। जिन्दगी में जो आघात मिले, उन्हें अपनी झोली में समेट कर हिम्मत दिखायी है।

कवि ने अपने जीवन के सामाजिक दुःख-दर्द और अभाव को सहर्ष स्वीकार किया है और इनके बीच से मनुष्य को सामाजिक जीवन जीने की राह दिखाई है। आचार्य जानकीवल्लभ शास्त्री की रचनाओं में क्लासिकल छायावादी, प्रगतिशील और प्रायोगिक प्रवृत्तियाँ पाई जाती हैं, इसलिए किसी एक घेरे में बांधकर उनका समग्र मूल्यांकन नहीं किया जा सकता। उनका क्लासिकल और छायावादी रूप अधिक व्यापक है उसे पहचानने में ज्यादा दिक्कत नहीं होती है। इस प्रकार शास्त्री जी का सृजन विकास जीवन और जगत को आत्मसात् करके हुआ है। इनका काव्य फलक व्यापक है, इन्होंने छायावादियों की तरह प्रकृति चित्रण में तन्मयता दिखाई है तो प्रगतिवादियों की भाँति चरमराते सामन्तवाद के खोखलेपन को भी उजागर किया है यथा -

“उस युग की संस्कृति का खण्डर शेष है,

सम्राटों, सामन्तों का स्वर शेष है,

सदाचार का आडम्बर भर शेष है,

कुछ, पूजाघर, चिड़ियाघर शेष है।"17

आचार्य जानकीवल्लभ शास्त्री सामाजिक यथार्थवादी कवि हैं। अतः इन्होंने अपने युग की सामाजिक विकृत्तियों का यथार्थ चित्रण अपनी साहित्यिक कृतियों के माध्यम से किया है।

आज कविता में नये प्रयोगों के युग में भी कवि अपने संस्कारों की रक्षा में सजग है-उन पर पंत जी जैसा समय का राजनैतिक प्रभाव प्राय: नहीं पड़ा है। इसका यह अर्थ नहीं है कि कवि युग चेतना के साथ संवेदनशील नहीं है कवि की कविताओं में जीवन की अनुभूतियों एवं शाश्वत सत्य की अभिव्यक्ति के साथ ही साथ युग सम्बंध सामाजिक राजनैतिक गतिविधियों की यथार्थता के भी चित्र मिलते हैं।

दलित वर्ग के प्रति कवि की सहानुभूति इतनी तीव्र है कि उसने आस्तिकता आध्यात्मिकता भी उसी पर न्योछावर कर दी। वह अपने आराध्य को इसी वर्ग में प्रतिष्ठित पाता है। उसका विश्वास है कि उसे गूदड़ियों में लिपट दीन-दुखियों की निरीह आत्माओं में देखा जा सकता है।

"छीने कौन गुदड़ियों में, किसने मुझको पहचाना?

आह, तभी जीवन धन मेंने, लिया फकीरी बाना।'18

आचार्य जानकीवल्लभ शास्त्री ने अपनी काव्य रचनओं में अपने युग के सामाजिक जीवन का यथार्थ चित्रण कर कवि समाज के लोगों को सावधान रहने के लिए सावधान किया है - 'सावधान' कविता के माध्यम से -

काँटों में खिलना है सुमन सावधान!

घेर रहा अंधकार; गगन, सावधान!

बन्ध न सम्बन्ध-सूत्र बनता

उच्छंखल मन तन से तनता,

बचना है, रचना की लगन, सावधान!

घेर रहा अंधकार गगन, सावधान!

भाषण प्रवचन के दिन बीते, रीते अनुभव मीठे-तीते,

कर्म है कठोर, मृदुल वचन सावधान!

घेर रहा अंधकार; गगन, सावधान!

आचार्य जानकीवल्लभ शासत्री ने अपने समय के समाज में होने वाले सामाजिक संघर्ष को साहसपूर्वक झेला जैसा कि कवि निराला ने। छायावादोत्तर काल के कवि शास्त्री जी ने प्रगतिशील कवि निराला की भाँति अपनी काव्य रचनाओं में आत्म संघर्ष तथा सामाजिक संघर्ष का यथार्थ चित्रण भावपूर्ण ढंग से किया। आज भी आचार्य जानकीवल्लभ शास्त्री की कुछ रचनाऐं जो कभी बहुत पहले पढ़ी थी वे आज भी स्मरण आने पर सामाजिक जीवन में नवीन ऊर्जा का संचार करती है जैसे - 
“मैं न गगन हूँ, मैं न यही हूँ।

जिस नाम से मुझे पुकारो,

उसी रूप का बना वही हूँ।'19

निष्कर्ष के रूप में कहा जा सकता है कि आचार्य जानकीवल्लभ शास्त्री ने अपनी काव्य रचनाओं में प्रगति, परम्परा व प्रयोग के साथ-साथ प्रगतिशील जीवन मूल्यों तथा सामाजिक जीवन का यथार्थ चित्रण अपनी काव्य रचनाओं में किया है जिस प्रकार प्रगतिशील कवि निराला ने अपनी रचनाओं में 'बादल राग' नाम से कितनी ही कविताऐं लिखीं तथा बादल को क्रान्ति का प्रतीक मानकर समाज के लोगों को क्रान्ति के लिए सचेत किया तथा अपने समय के सामाजिक जीवन संघर्ष का यथार्थ चित्र प्रस्तुत किया है। निराला के समान शास्त्री जी को भी बादल प्रिय विषय रहा है। शास्त्री जी ने निराला के समान बादलराग का संग्रह ही तैयार कर लिया। ऐसे तो बादल राग पर पंत की भी एक कविता है परन्तु वह बिल्कुल रूमानी-प्रकृति की कविता है। शास्त्री जी ने निराला का अनुसरण किया है, पंत का नहीं, अपने मेघपरक गीतों में शास्त्री जी ने अपने मेघगीत की पार्श्विका में श्रृंगार के संयोग, वियोग तथा प्रेम की विभिन्न मनःस्थितियों का चित्रण तो किया ही है, प्रतीक-पद्धति में सामाजिक तथा राजनैतिक अनाचार पर करारा व्यंग्य किया है तथा समाज के निम्न मध्यम वर्ग किसान, मजदूर, पूँजीपति, सर्वहारा आदि का यथार्थ चित्रण किया है।

\section{संदर्भ-}

1. आचार्य जानकीवल्लभ शास्त्री-पाठक मारूतिनन्दन : समकालीनों की दृष्टि में, पृ. 148

2. आचार्य जानकीवल्लभ शास्त्री-षिप्रा, पृ. 45

3. आचार्य जानकीवल्लभ शास्त्री-गाथा, पृ. 34

4. आचार्य जानकीवल्लभ शास्त्री-गाथा, पृ. 36

5. आचार्य जानकीवल्लभ शास्त्री-गाथा, पृ. 38

6. आचार्य जानकीवल्लभ शास्त्री-गाथा, पृ. 65

7. आचार्य जानकीवल्लभ शास्त्री-रूप-अरूप, पृ. 35

8. आचार्य जानकीवल्लभ शास्त्री-रूप-अरूप, पृ. 38

9. आचार्य जानकीवल्लभ शास्त्री-बाललता पृ. 62

10. आचार्य जानकीवल्लभ शास्त्री-भिक्षुक (बाललता) पृ. 36

11. आचार्य जानकीवल्लभ शास्त्री-बाललता पृ. 41

12. आचार्य जानकीवल्लभ शास्त्री-बाललता (राजा के बगीचे में) पृ. 32

13. आचार्य जानकीवल्लभ शास्त्री-बेला, पृ. 52

14. आचार्य जानकीवल्लभ शास्त्री-बेला, पृ. 53

15. आचार्य जानकीवल्लभ शारत्री-मेरे पथ में न विराम रहा, पृ. 126

16. आचार्य जानकीवल्लभ शास्त्री-मेरे पथ में न विराम रहा, पृ. 128

17. आचार्य जानकीवल्लभ शास्त्री-पाठक मारूतिनन्दन : समकालीनों की दृष्टि में, पृ. 283

18. आचार्य जानकीवल्लभ शास्त्री-रूप-अरूप, पृ. 76

19. आचार्य जानकीवल्लभ शास्त्री-मेरे पथ में न विराम रहा, पृ. 84 